\title{
MARTÍN LUTERO Y LAS CONCEPCIONES DE DERECHO Y VIOLENCIA EN LA MODERNIDAD
}

\author{
Hernán Gabriel Borisonik*
}

Resumo: Ao contrário das concepções modernas, na Antiguidade, a cidadania era compreendida em função do direito político, enquanto a violência era precipitada (espacial quanto temporalmente) fora da polis. No presente artigo, serão analisados alguns pontos que tem feito da Reforma Protestante um dos marcos fundacionais da política moderna ocidental. Em concreto, serão examinadas as concepções de direito, cidadania e violência, com as quais Lutero contribuiu ao pensamento político e social, enquanto partiu de uma nova concepção do indivíduo, da consciência e da relação entre a política e a sacralidade.

Palavras-chave: Lutero, Direito, Violência, Cidadania.

Abstract: Unlike the modern conceptions, in the Antiquity, citizenship was understood according to the political rights, whereas the violence was thrown (so much spatial as temporarily) out of the polis. This paper will trace the drifts that made the Lutheran Protestant Reform one of the milestones of the modern western politics. This way, we will analyze the conceptions of justice, citizenship and violence with which the German theologian has contributed to the political and social thought, based on a new idea of the individual, the conscience and the relation between politics and sacredness.

Keywords: Luther, Justice, Violence, Citizenship.

* Doutor em Ciências Sociais e professor do Instituto de Investigación Gino Germani da Universidad de Buenos Aires. E-mail: hborisonik@sociales.uba.ar 
$|170|$

Martín Lutero y las concepciones de derecho...

Hace casi un siglo, Walter Benjamin ya había demostrado claramente que "la tarea de una crítica de la violencia puede definirse como la exposición de su relación con el derecho y con la justicia" (1991, p. 7). Con ello, expresaba que el vínculo entre ambos polos es tan íntimo y vigoroso que su sola denuncia ya era una gran parte del trabajo necesario para poder observar con profundidad el rol que cada uno de ellos cumple en las sociedades y el modo en el que podría, incluso, pensarse en formas diferentes de articularlos.

Al contrario de las concepciones modernas, en la Antigüedad, la ciudadanía era comprendida en función del derecho político, mientras que la violencia era precipitada (tanto espacial como temporalmente) fuera de la polis. En ese sentido, la Reforma Protestante ha formado parte del marco fundacional de la Modernidad política occidental. Por ello, el objeto del presente artículo es analizar la relación entre derecho y violencia en la Reforma protestante, tomando como categoría central a la ciudadanía y dejando establecidos algunos puntos medulares del pensamiento político que aparece en los escritos de Martín Lutero, en tanto que principal exponente teórico de tal acontecimiento. En concreto, serán examinadas los conceptos de derecho, ciudadanía y violencia, con las que Lutero realizó una contribución (tal vez sin tener esa intención) al pensamiento político y social, al haber partido de concepciones específicas de individuo, de consciencia y de la relación entre política y sacralidad.

Para ello, será necesario comenzar trazando una comparación con la tradición antigua, frente a la cual el legado luterano constituyó un importante punto de quiebre, fundamentalmente en referencia a la idea de la ciudadanía, que, en la Antigüedad, era comprendida en función de los derechos políticos más que de la territorialidad, mientras que la violencia era arrojada (tanto espacial como temporalmente) a ámbitos ajenos a lo político. Por su parte, se observa que las bases de la ciudadanía 
en la Modernidad se han asentado sobre la idea de patria y el uso de la violencia.

$\mathrm{Al}$ respecto, una de las pretensiones centrales de este trabajo es poder ver cómo algunos rasgos que conforman la concepción actual de ciudadanía tienen sus raíces en el pensamiento luterano. De allí se deriva el gran interés por establecer cómo se estructuró la relación entre justicia, ley y violencia en la Reforma protestante.

Para comenzar, entonces, es importante delinear las características fundamentales de la estructuración del vínculo entre derecho y violencia en la Antigüedad, así como repasar la idea de ciudadanía que encarnaba dicha relación.

En términos generales, la ciudadanía griega estaba caracterizada por la participación en la deliberación de los asuntos públicos, es decir, comunes a todos. La polis griega (sobre todo en su etapa democrática) intentó constituirse como un espacio en el que primaba la palabra, un espacio constituido al superar las necesidades básicas para la reproducción de la vida, un espacio que se definía fundamentalmente por ser el que permitía la realización humana, a través de la actividad política.

Por otro lado, la ciudadanía en Grecia era portadora de un fuerte componente elitista, dado que, en definitiva, muy pocos podían acceder al status de ciudadano: era obligatorio ser varón, mayor de edad, tener una determinada renta y (en casi todos los casos) poder demostrar la pertenencia "racial" y religiosa a la polis en cuestión. Es más, la exclusión de la ciudadanía funcionaba en ambos extremos de la sociedad. Por un lado se encontraban aquellos que estaban por debajo de la línea necesaria para ser considerados ciudadanos: los esclavos, los extranjeros, las mujeres, los niños, los hombres libres sin renta. Todos ellos se desenvolvían en ámbitos no políticos, tales como el comercio, el oikos, etc., con lo cual, sólo algunos pocos lograban el acceso al ámbito público por excelencia, es decir, la deliberación de los asuntos comunes, a través de la acción política y gracias a estar liberados del trabajo manual. 
Asimismo, aquellos considerados "demasiado grandes" también eran quitados de las actividades públicas, dado que se temía que ejercieran un desequilibrio institucional, por lo cual se tendía a castigarlos con el ostracismo (Aristóteles, 2000, pp. 1311-1313) $)^{1}$.

Como puede notarse, la pretendida igualdad absoluta que existía entre los ciudadanos era una construcción jerárquica (y política) que dejaba afuera a la mayoría de los habitantes de la polis. En palabras de Arendt,

\begin{abstract}
a igualdad dentro del marco de la ley, que la palabra isonomía sugería, no fue nunca la igualdad de condiciones [...] sino la igualdad que se deriva de formar parte de un cuerpo de iguales. [...] La diferencia entre este concepto antiguo de igualdad y nuestra idea de que los hombres han nacido o han sido creados iguales y que la desigualdad es consecuencia de las instituciones sociales y políticas, o sea, de instituciones de origen humano, apenas necesita ser subrayada. La igualdad en la polis griega, su isonomía, era un atributo de la polis y no de los hombres, los cuales accedían a la igualdad en virtud de la ciudadanía, no del nacimiento (Arendt, 1988, p. 31).
\end{abstract}

Al contrario, la constitución de la identidad política en Roma se dio recorriendo el camino de modo inverso al del modelo griego. La experiencia política fue incluso más central para Roma que para Grecia, donde, si bien la ciudadanía era la base fundamental de la vida pública, política y naturaleza (o biología) estaban ligadas. Era la misma actividad política (vista como obvia,

\footnotetext{
${ }^{1}$ He trabajado específicamente tal cuestión en: Borisonik, Hernán (2011). “Del exiliado al apolítico: el ostracismo en Aristóteles", en Burello, Marcelo; Ludueña Romandini, Fabián; Taub, Emmanuel (Editores). Políticas del Exilio. Orígenes y vigencia de un concepto, Buenos Aires: Eduntref.
} 
natural, para un griego) la que otorgaba, a fin de cuentas, la ciudadanía. Pero el acceso a los derechos civiles estaba restringido por el nacimiento. La romanidad, en cambio, no suponía un comportamiento cultural único. Tenía que ver con la forma, no con el contenido, por lo tanto cualquier hombre podía devenir romano. Roma elaboró un modelo de ciudadanía específico, donde el ciudadano era siempre un extranjero convertido en romano. Así, la pertenencia a la comunidad de derecho era independiente del origen racial de cada uno.

A diferencia de la supuesta ahistoricidad y naturalidad de la polis (la homophylia griega), la ciuitas romana era una asociación artificial entre pueblos de orígenes diferentes. Inversamente que en Grecia (donde los gobernantes eran hermanos y ciudadanos), la ciudadanía romana era algo que hermanaba a los hombres $a$ posteriori.

Otra diferencia es que en Grecia la política estaba determinada solamente por aquellas personas a las que estaba destinada, mientras que en Roma era el pueblo en un sentido mucho más amplio el que se veía afectado por la actividad de quienes accedían a los cargos políticos.

Sea como fuere, lo que compartían estos dos modelos (los más importantes de la antigüedad) era que, respecto de la ciudadanía, los derechos políticos valían más que la mera territorialidad. En el caso griego, el nacimiento era una condición necesaria, pero no suficiente para ser ciudadano, mientras que en Roma, el desapego de lo territorial era aun mayor, dado que romano era una expresión que se extendía casi universalmente.

En ese sentido, es fundamental prestar atención al valor de la ley frente a la violencia. En la polis griega, la palabra era el mecanismo fundamental para resolver los conflictos, dejando a la fuerza física como atributo de los bárbaros, los no desarrollados. Incluso, el enfrentamiento entre poleis griegas era llamado discordia y no guerra. De hecho, Platón llegó a sostener que

el nombre de la discordia se aplica a la enemistad entre allegados, y el de guerra a la enemistad entre 


\begin{abstract}
extranjeros. [...] Sostengo que los de raza griega son parientes y allegados entre sí, y que son en cambio, ajenos y extranjeros para los bárbaros [...]. Por lo tanto, cuando los griegos luchen con los bárbaros y los bárbaros con los griegos diremos que están en guerra y que son enemigos por naturaleza, y será preciso dar el nombre de guerra a esta enemistad; pero cuando luchen griegos contra griegos, hemos de afirmar que son en verdad amigos por naturaleza, pero que Grecia se halla circunstancialmente enferma y dividida y será preciso dar el nombre de discordia a esta enemistad (Platón, 1997, p. 430 b-d).
\end{abstract}

En ese mismo sentido es que Francis Wolff llega a afirmar que cuando cayó la polis (en tanto que forma de organización), la actividad política cedió su lugar a la mera aplicación de los designios imperiales: "Es cierto que, después de la conquista alejandrina, cuando todos dependían del mismo rey de Macedonia, y las ciudades habían perdido su autonomía, los griegos, en un cierto sentido, ya no «harían» más política" (Wolff, 1999, pp. 9-10).

Ahora bien, como es ya conocido, el hundimiento político de Roma, durante el siglo V, supuso, a su vez, el final de cierto complejo de ideas acerca de la pertenencia comunitaria. La disgregación política y la dispersión de comunidades enteras, como consecuencia de los flujos de invasiones y migraciones, impuso una serie de mecanismos vinculares fundamentados sobre la coacción.

El corporativismo y las relaciones sociales feudales diluyeron el concepto de ciudadanía. Unos pocos resquicios identitarios quedaron restringidos, básicamente, a los gremios y los feudos. Sólo los señores y los maestros tenían autonomía personal y algún protagonismo social. Como resultado de tal proceso histórico, surgieron una serie de príncipes y señores que encarnaban al poder que ya no estaba cargado con la idea de creación colectiva, sino de coerción física. 
Frente a la gran disgregación política que significó la mencionada fragmentación del poder durante la época feudal, se hizo presente, como contrapartida, una idea de universalidad impuesta por el cristianismo. Ante la caída del imperio que la había difundido, la iglesia católica se convirtió paulatinamente en una especie de gran paraguas que cubría a toda Europa, estableciendo un paradigma moral y religioso que les permitió construir un modelo ético común. Pero esa gran autoridad moral dio al Vaticano una enorme concentración de poder político, lo cual, según ciertas interpretaciones, iba en contra del mensaje cristiano.

Entonces, de cara a una Europa políticamente desintegrada y a una iglesia extremadamente poderosa, surgió una revisión del cristianismo que encontró a su máximo exponente en Martín Lutero. Respecto de la Reforma protestante, es preciso tener siempre en cuenta que Lutero, así como la enorme mayoría de quienes llevaron adelante tal movimiento, fueron teólogos y no pensadores políticos, por lo cual "no debemos pedirles que nos presenten una filosofía política completa ni una teoría general de la política. [...] Ellos consideraron que sus afirmaciones en materia de política se derivaban directamente de sus premisas teológicas" (Forrester, 1963, p. 305). Y sin embargo, como bien lo explica Wolin, "aunque sería infructuoso negar la primacía de los elementos teológicos en el pensamiento de Lutero, es erróneo deducir de ello que haya sido ajeno al interés por la actividad política" (Wolin, 1993, p. 157). Lutero no fue un intelectual ni apoyó al intelectualismo ${ }^{2}$, y por ello su discurso era más el de un profeta que el de un teórico.

Por otra parte, si bien existen claros aspectos conservadores $\mathrm{y}$ reaccionarios en sus escritos, y aunque eso no haya sido anticipado ni deseado inmediatamente por Lutero, la Reforma

${ }^{2}$ Importa aclarar que si bien Lutero no era un anti-intelectual, sí fue muy crítico de la razón escolástica. 
|176 |

Martín Lutero y las concepciones de derecho...

protestante ha dado lugar al despliegue de toda una serie de concepciones que han caracterizado al mundo moderno. Asimismo, el luteranismo acabó por ser una especie de catalizador o potenciador de la cultura moderna, bajo mediaciones tales como la secularización estatal, la libertad de conciencia, la concentración del poder político, la irrupción definitiva de la individualidad (e, incluso, de la idea de subjetividad), el trabajo como valor, la racionalidad instrumental, el eclipse del poder político del Vaticano, etc. Todos estos aspectos han provocado que, desde sus mismos orígenes, la Reforma implicara una mutua imbricación entre política y religión ${ }^{3}$.

Tal vez podría tomarse como punto de partida, en esta ocasión, a la distinción establecida por Lutero entre los denominados reino temporal [weltlich] y reino espiritual [geistlich]. Al aplicar esta separación, el fraile alemán realizó simultáneamente dos movimientos. En primer lugar, dejaba sentada su oposición a la división jurídica que había realizado la Iglesia romana (la cual, gracias al esfuerzo de sus canonistas, había integrado el derecho romano a su sustancia) entre las leyes para los laicos y aquellas para el clero. Lutero se ha opuesto a tal clasificación. De hecho, no parece casual que una de las obras que quemó en el inicio de su revuelta haya sido el volumen de las Decretales (normas papales pertenecientes al derecho canónico medieval).

De acuerdo con Lutero, sobre la tierra no debía existir ningún tipo de privilegio legal para los hombres de la Iglesia, dado que, en realidad, todos los mortales poseen los mismos derechos, y se diferencian solamente en cuanto a sus funciones.

\footnotetext{
${ }^{3}$ Una referencia obligada al respecto es la obra de Ernest Troeltsch, quien intentó sostener que Lutero representaba una continuación de la teología medieval católica, en tanto que "cultura guiada sobrenaturalmente" (Troeltsch, 1951, p. 46). Sin entrar en tal disputa, el intento de nuestros párrafos es quitar de la discusión la pertenencia de este autor (claramente transicional) a una u otra tradición, para prestar más atención al legado de su obra.
} 
Por lo tanto, la institución eclesiástica no tenía, para Lutero, ningún tipo de centralidad ni, mucho menos, potencia política. Tal y como lo resume Quentin Skinner, para Lutero "la verdadera iglesia no tiene existencia real, salvo en los corazones de sus fieles seguidores" (Skinner, 1993, II, p. 17). Pero complementariamente, al separar lo temporal de lo espiritual, Lutero dejaría a Dios el cuidado de las almas y entregaría a los príncipes el control absoluto de los cuerpos. En otros términos, mientras que el foro interno e inmaterial era gobernado religiosamente, todo aquello que perteneciera al mundo sensible y que pudiera verse reflejado en comportamientos externos debía ser regido por la espada secular ${ }^{4}$.

Ciertamente, era tal su desapego de los ideales antiguos (y particularmente a los griegos) que equiparaba al gobierno político con el uso de la violencia, mientras que rechazaba al logos como capacidad humana de organización social. De ese modo, al tiempo que censuraba cualquier tipo de distinción jerárquica entre cristianos, afirmaba una jerarquía absoluta en el nivel político. Incluso el propio Lutero llegó a proclamar que, desde los tiempos de los Apóstoles hasta la Reforma, nadie había ponderado más que él a la autoridad terrenal, dado que reconocía al gobierno civil como legítimo por Dios, y ya no a través de la mediación de la Iglesia (Lutero, 1966). Así, Lutero otorgaba al poder político una función sagrada y una dignidad divina, hasta entonces inéditas. En resumen, su teoría de los dos reinos (Zwei-Reiche), cada uno con su respectivo gobierno (Regiment), expondría una imagen del mundo en la cual Dios deseaba con tanta fuerza al cuerpo clerical como al gobierno político.

De todas maneras, Lutero tuvo por las cuestiones jurídicas una atención muy despreciativa. Fueron las circunstancias (la guerra de los campesinos, la necesidad de dotar efectivamente al pueblo luterano de un sustituto de las antiguas directivas

${ }^{4}$ Existen otras miradas sobre esta cuestión, que ven en el planteo de Skinner un forzamiento de las palabras luteranas. Un ejemplo es el de Ulrich Duchrow, quien habla del uso y abuso de su teología. 
romanas) las que lo movieron a mezclarse con los temas seculares. Y aún así, lo hizo con reticencia, pues sostenía que las lecciones del Evangelio no tenían relación con las cosas del mundo terrenal, dado que se consagraba a lo espiritual. Por el contrario, dejaba en manos de los príncipes y señores seculares el control de lo temporal.

El "principio material de la Reforma" es que el hombre sólo es justificado por la fe, no por las obras. Ni las prácticas religiosas (tales como la obtención de indulgencias) ni la vida moral (la abstención del robo, la mentira o la fornicación) tienen algún valor justificante. Con ello, Lutero desvinculaba a la acción de la salvación. El anterior es un rasgo moderno que se presenta en el pensamiento luterano, dado que coloca a la relación con Dios en el plano de lo individual. Precisamente, una obra central de Lutero al respecto, tiene por título Sobre la libertad cristiana, lo cual permite observar hasta qué punto el tema le preocupaba. Sin embargo, es necesario aclarar que, en su pensamiento, esta libertad no juega más que el plano religioso. Es desde el punto de vista de la salvación (único que cuenta para un monje) que el cristiano es totalmente libre respecto de cualquier ley y de toda norma jurídica. En la vida cristiana perfecta no existe nada jurídico "Si el cristiano no ha de necesitar obra alguna, queda ciertamente desligado de todo mandamiento o ley; y si está desligado de todo esto, será por consiguiente libre" (Lutero, 1966, p. 152).

Pero, al mismo tiempo, Lutero bregaba por un orden severo apoyado sobre la fuerza y la violencia. Dentro de su planteo, los preceptos evangélicos y la no resistencia al mal sólo corresponden al individuo, pero no a la autoridad en cuanto tal. Es decir, tales normas no obligan al príncipe, o al policía o a aquel que ha recibido la vocación de controlar y castigar. Para él, el orden es tan providencial como la fuerza que lo sirve.

Dios honra tan grandemente la espada que la nombra su orden propio... también la mano que porta esa espada y que degüella, no es la mano del hombre, sino la de Dios; y no es más el hombre sino Dios que 


\begin{abstract}
pena, tortura, decapita, degüella y hace la guerra, y todo ello son sus obras y sus juicios. [...] No es necesario considerar en el oficio de la guerra, de que, manera degüella, tortura, mata, captura [...]. Esos son los ojos cerrados y muertos de los niños que lo hacen y que en el médico no ven la ventaja que surge del corte de una mano o la separación de una pierna, que no remarcan su necesidad para salvar todo el cuerpo. Por eso es necesario considerar con ojos de hombre la razón por la cual el oficio de la guerra o de la espada degüella o actúa con crueldad; se considerará entonces que ese oficio es divino en sí y que él es tan útil y necesario al mundo como el comer y el beber o cualquier otra obra (Lutero, 1966, p. 312).
\end{abstract}

Teniendo en cuenta lo anterior, ¿cómo concilia Lutero la doctrina de la libertad cristiana con su defensa de un gobierno secular fuerte y prácticamente absoluto? Lo hace a partir de la idea de que la libertad cristiana sólo tiene valor para los verdaderos cristianos. Pero dado que existen muy pocos en este mundo, incluso ellos deben obedecer la ley civil, dado que sin ella todo sería un caos, y por ende el reino secular existe por designio divino. Pero el desdén por el derecho que presenta Lutero no responde más que a su menosprecio generalizado por todo lo terrenal: visto que la verdadera justicia es cosa divina, lo que ocurra con el derecho secular posee una importancia relativa. De todas formas, es necesario volver a aclarar que Lutero planteó un divorcio definitivo entre la justicia divina y aquella impartida por los hombres religiosos. De hecho, el modo de derribar la denominada primera muralla de los romanistas consiste en mostrar cómo la única ley que tiene valor sobre la tierra es aquella que emana de los príncipes, y no la creada por el papa (Lutero, 1966). Por el contrario, los hombres del clero deben obedecer a la ley secular del mismo modo que cualquier laico, puesto que la justicia divina sólo se busca y se obtiene con el alma, no con el cuerpo. 
$\mid 180$ |

Martín Lutero y las concepciones de derecho...

Adicionalmente, existe una fuente bíblica sobre la que Lutero basa su apoyo a la espada secular, que se encuentra en la Epístola a los Romanos 13,1-8, donde San Pablo dice: "Sométase todo individuo a la autoridad, al poder, pues no existe autoridad sin que Dios lo disponga; el poder, que existe por doquier, está establecido por Dios. Quien resiste a la autoridad resiste al orden divino. Quien se opone al orden divino, se ganará su condena". Entonces, si bien, no tiene poder alguno sobre las almas, el gobierno político es ilimitado en lo que concierne a los cuerpos y los comportamientos.

De lo anterior se deriva una especie de duplicación legal que atraviesa a los hombres: mientras que su fe y sus almas son regidos directamente por Dios y las Escrituras, sus vidas materiales y sus actos exteriores deben someterse absolutamente a la justicia secular, derivada del poder sagrado de los Estados. Tal duplicación responde directamente a que existe, ya en Dios, una estructura dual, en la que la creación se da por medio del verbo, pero la conservación del orden está vinculada con la acción, con la materialidad. La doctrina de los dos reinos se encuentra expuesta principalmente en la obra Sobre la Autoridad Secular: Hasta donde se le debe obediencia, escrita en 1523. Allí, Lutero distingue dos reinos según los miembros que forman parte. Uno es el reino de los hijos de Adán y el otro, el reino del mundo. La adscripción a cada uno de éstos se origina de acuerdo a la respuesta que cada uno de los hombres da a la llamada de Cristo.

No obstante, en lo que concierne a la vida terrena, tal duplicación es superflua, puesto que sólo los príncipes deben gobernar sobre los cuerpos. Este tipo de afirmación lleva a pensar en una favorable predisposición del reformador hacia una concepción monista de la sociedad - la misma que predomina bajo el régimen político del Estado moderno, en oposición a la propuesta del poder disgregado universalista del mundo medieval. En otros términos, si bien Lutero considera al universo espiritual el más importante, al mentar la sociedad terrenal no responde a otro amo que el príncipe secular. 
Otra característica relevante de la posición luterana frente al derecho está relacionada con el carácter punitivo, represivo, de éste. "La espada secular existe para castigar a los malos y proteger a los buenos" (Lutero, 1966, p. 202). El poder no es creativo, no es potencia, sino que es coerción y sostén de un orden sacralizado. El símbolo por excelencia del derecho es, para Lutero, la espada, no la balanza.

Además, el buen derecho es aquel que está en concordancia con la Biblia. A Lutero no le interesa que la ley sea un producto de la razón humana, ni que se adecue a la forma de vida de un pueblo, sino que debe apegarse con la mayor rigurosidad posible a las sagradas escrituras (las que, de no existir hombres no cristianos, deberían ser la única ley). El gran valor que Lutero le asigna a la vida cristiana no está basado en el derecho, sino en la fe y la caridad. Lutero señala con bastante frecuencia que antes la persona tiene que ser justa para que después sus obras también puedan serlo. La persona se vuelve justa sólo a través de la fe en el Evangelio. Las obras pueden ser justas pero no por sí mismas sino a través de la fe, mediante la renuncia a la fama y a la honra propia.

Al igual que en la doctrina ciceroniana, la ley positiva, humana, no puede nunca contradecir a las sagradas escrituras. Quien ejerce la justicia terrenal debe obedecer, simultáneamente a la ley divina.

Dado que la naturaleza humana está caída desde el pecado original, el derecho no puede fundarse en ella, sino controlarla, reprimirla. La pretensión de confiar la justicia a la razón humana era, para el fraile alemán, pura soberbia. Su desprecio por el humanismo renacentista ( $\mathrm{y}$ su célebre debate con Erasmo) tiene el mismo sentido. La ley, cualquiera que sea, exige tanto que es absolutamente evidente al pecador cuán lejos se encuentra de sus exigencias. La consecuencia que se deriva de esto es que resulta imposible todo intento de hacer mérito de parte de los hombres.

Por ello, la justicia para los cristianos debe basarse en poner la otra mejilla, en aceptar la violencia y situar al prójimo siempre 
$|182|$

Martín Lutero y las concepciones de derecho...

antes que a sí mismos: "Sufrimiento, sufrimiento, cruz, cruz, ese es el derecho de los cristianos" (Lutero, 1966, p. 376). Lutero exige un absoluto amor a Dios (bajo negativa de amor propio), un absoluto temor a Dios (bajo negativa de cualquier temor a hombres o poderes) y una absoluta confianza en Dios (bajo negativa de toda autoconfianza), en contra los pecados fundamentales de la presunción y la soberbia.

Otro tema central a la hora de analizar la relación entre derecho y violencia en el pensamiento luterano, es la cuestión del derecho a resistir las órdenes del príncipe. Al respecto, es interesante la lectura de los escritos de Lutero Contra las hordas criminales y saqueadoras de los campesinos. Cabe recordar que los campesinos se habían sublevado en nombre del Evangelio, figurándose que Lutero los apoyaría, puesto que defendían la caída de ciertas jerarquías ${ }^{5}$. El líder de la iglesia protestante, por el contrario, tomó partido en favor de los señores. Con una violencia notable, anatemiza la audacia de haber osado rebelarse en nombre del Evangelio cuando este Libro Sagrado no conoce más que la obediencia.

En tercer lugar: decís que la autoridad es demasiado mala e intolerable, porque no nos permite predicar, el Evangelio, nos oprime con sus cargar sobre nuestros bienes temporales y nos echa a perder en cuerpo y alma. Yo respondo que el que la autoridad sea mala e injusta no excusa el motín o la rebelión. Castigar la maldad no corresponde a cualquiera sino a la autoridad secular, que lleva la espada como dice

\footnotetext{
${ }^{5}$ En ese sentido, cabe recordar la discusión entre Lutero y Thomas Müntzer acerca de los dos poderes (religioso y temporal). Mientras que el primero, a través de la idea de la gracia divina, acepta a toda autoridad terrena, el segundo (que terminó alejándose de Lutero y liderando movimientos campesinos) comprendía a la fe como fuertemente inserta en el terreno de lo social, y por ello defendía la posibilidad de levantar las armas contra los príncipes. Pues, si bien Müntzer no negaba a la gracia, sí le otorgó un papel secundario en comparación con Lutero.
} 


\begin{abstract}
San Pablo en Rom. 13,4". [Y luego], aceptado que los señores hayan cometido una injusticia, mas no sería igualmente justo y equitativo el cometer igual injusticia, es decir desobedecer y destruir el orden que ha sido establecido por Dios y que no nos pertenece; por el contrario, es necesario sufrir la injusticia; si un príncipe o un señor no quiere tolerar el Evangelio, idos a otros principado..., porque Cristo dijo: "si os persiguen en una ciudad, id a otra" (Lutero, 1966, pp. 503-504).
\end{abstract}

No existe, en Lutero, derecho alguno a la rebelión contra el poder político, ni resistencia a la autoridad, pues ésta está impuesta por Dios y debe ser considerada su espada en la tierra.

Para concluir, si bien la concepción luterana del derecho es claramente conservadora, en su pensamiento se hacen presentes cuestiones que abrieron la puerta a la Modernidad, tales como la individualidad y la libertad de conciencia, la traducción de la Biblia al alemán, etc.

En pocas palabras, la doctrina de Lutero se basa en la existencia de dos jurisdicciones, cada una con derechos y gobiernos diversos: sobre las almas sólo Dios y sobre los cuerpos sólo el poder secular. De ese modo, los verdaderos cristianos deben fundar sus vidas en la Biblia y en la doctrina cristiana, pese a que todos los mortales están igualmente afectados por la ley secular. Y sin embargo, al pertenecer la espada al designio divino, puede afirmarse que, en última instancia, el poder secular también se sacraliza y se torna absoluto. Así y todo, la violencia pasó a reemplazar a la acción política, en lo que respecta a los actos de gobierno, frente a la cual no hay posibilidad alguna de rebelión o resistencia.

Finalmente, el pensamiento de Lutero significó, sin duda, un hito importante dentro del proceso de transición entre la Antigüedad y la Modernidad. De hecho, además de haber ejercido una cierta influencia sobre la aparición de los hábitos de lectura y escritura individual, la Reforma protestante fue uno de los 
| 184 |

Martín Lutero y las concepciones de derecho...

factores clave para concebir a la ciudadanía y al derecho de modo renovado. Precisamente, el período siguiente a la Reforma, que constituyó el caldo de cultivo para la Revolución francesa, estuvo caracterizado por una gran mutación del vínculo entre lo que se pensó como el ámbito privado y el ámbito público. De modo que, frente al ideal antiguo de la polis y la plaza pública como espacios de realización humana (permaneciendo lo privado como asociado a la supervivencia y reproducción de la vida), en la Modernidad comenzó paulatinamente a pensarse lo público como el lugar del poder absoluto, de la violencia, de manera que la esfera privada se erigió como espacio de reflexión, palabra y realización subjetiva, en el cual las relaciones son horizontales y existe libertad de pensamiento. $\mathrm{Y}$ en cada uno de estos aspectos puede rastrearse una raíz luterana, atravesada por todas las mediaciones que se han presentado.

\section{Bibliografia}

ARENDT, H. Sobre la revolución. Madrid: Alianza, 1988.

ARISTÓTELES. Política. Madrid: Gredos, 2000.

BENJAMIN, W. Para una crítica de la violencia y otros ensayos. Madrid: Taurus, 1991.

BORISONIK, H. “Del exiliado al apolítico: El ostracismo en Aristóteles". In: BURELLO, M; LUDUEÑA ROMANDINI, F; TAUB, E.(eds). Políticas del Exilio. Orígenes y vigencia de un concepto, Buenos Aires: Eduntref, 2011.

DREHER, M. “Martinho Lutero (1483-1546) e Tomás Münzer (1489-1525): A justificação teológica da autoridade secular e da revolução política". Veritas, v. 51, n. 3. Porto Alegre, pp. 145-168. 2006.

DUCHOW, U. Os dois reinos: Uso e abuso de um conceito teológico. São Leopoldo: Sinodal, 1987. 
FORRESTER, D. "Martín Lutero, Juan Calvino". In: STRAUSS, Leo e CROPSEY, J. Historia de la filosofía política. México: FCE, 1963.

LUTERO, M. D. Martin Luthers Werke. Weimar: Hermann Böhlaus Nachfolger, 1966.

PLATÓN. República. Buenos Aires: Eudeba, 1997.

TROELTSCH, E. El protestantismo y el mundo moderno. México: FCE, 1951

SKINNER, Q. Los fundamentos del pensamiento político moderno. México: FCE, 1993.

WOLIN, S. Política y perspectiva. Buenos Aires: Amorrortu, 1993.

WOLLF, F. Aristóteles e a política. São Paulo: Discurso Editorial, 1999. 